\title{
Brockmanniana
}

\section{Reiner Brockmanni vanemate matusetrükised}

\author{
RAIMO RAAG
}

Artikli eesmärk on tutvustada kahest matusetrükisest lähtuvalt tulevase Tallinna gümnaasiumi kreeka keele professori ja juhuluuletaja Reiner Brockmanni (16091647) vanemaid ja pere suhtlusringkonda, täpsustada tulevase gümnaasiumiprofessori eluloo mõnda seika enne tema isa surma 1626. aasta suvel ning taasavaldada ja tuua teaduskäibesse luuletus, mille Brockmann kirjutas isa surma puhul. ${ }^{1}$

Omaaegse tava kohaselt võidi perekonnas kasutada põlvest põlve samu eesnimesid. Nii kannavadki mitmed käesolevas kirjutises esinevad isad ja pojad sama nime. Selguse huvides kasutan nende eristamiseks epiteete isa ja poeg: poeg Reiner Brockmann on Eesti kultuuriloos tuntud juhuluuletaja, isa Reiner Brockmann tema isa.

\section{Brockmanni vanemate matuste puhul ilmunud trükised}

See, et poeg Brockmann kirjutas oma isa surma puhul kreekakeelse leinaluuletuse, on olnud ammu teada. Friedrich Konrad Gadebusch (1777: 128-129) mainib seda oma kirjameeste leksikonis ja sellele toetudes on teavet praegusajani korratud, nt Brockmanni „Teoste” sissejuhatavates artiklites (Priidel 2000: 26; Telschow 2000: 36), samuti Tallinna XVII sajandi esimese poole kirjanduselule pühendatud Martin Klökeri monograafias (Klöker 2005a: 652, eestikeelses versioonis 2014: 250). Luuletust pole aga seni leitud, kuigi Gadebusch juhatab, kust otsida: „Mõlemale [st isa Brockmannile ja tema abikaasa Margareta Scheffterile] pidas Güstrow' superintendent Lucas Bacmeister leinajutlused, mis on trükitud” (1777: 128 - minu tõlge, R.R.). Gadebusch viitab leinajutlustele mitmuses, seega ilmneb, et talle oli teada, et poeg Brockmanni kummagi vanema mälestuseks ilmus eraldi matusetrükis. Mõlemad trükised on säilinud. Ema Margareta Scheffterile pühendatud matusetrükise (vt Bacmeister 1625) eksemplarid on tallel Göttingenis Alamsaksi riigi- ja ülikooliraamatukogus (Niedersächsische Staats- und Universitätsbibliothek), Braunschweigi linnaarhiivis (Stadtarchiv Braunschweig) ja Marburgi ülikooli raamatukogus (Universitätsbibliothek Marburg) (GESA: Scheffter, Margaret(h)a (9. VI 2020)). Isa matusetrükise eksemplare (vt Bacmeister 1627) säilitatakse Berliini riigiraamatukogus (Staatsbibliothek zu Berlin, Preußischer Kulturbesitz), Gotha teadusraamatukogus (Forschungsbibliothek Gotha) ja Hannoveris Alamsaksi liidumaa raamatu-

\footnotetext{
${ }^{1}$ Luuletus puudub Endel Priideli koostatud Brockmanni „Teostes” (Brockmann 2000). Väljaande ilmumise järel on leitud veel paarkümmend Brockmanni luuletust (Klöker 2005b: nr 88:4, 99:4, 115:3, 116:3, 117:4, 118:2, 118,2:1, 120:4, 127:4, 131:4, 138:3, 139:4, 150:4, 153:4, 155:4, 165:3, 169A,1:1, 169B,1:1, 169C,1:1, 169D,1:1, 171B:2, 175:4, 327:1; Viiding 2015: 783-789).
} 
kogus (Niedersächsische Landesbibliothek) (GESA: Brockmann, Reiner (9. VI 2020)). Poeg Brockmanni luuletus leidub isa surma puhul avaldatud trükises. Mõlemad väljaanded on trükitud Rostockis Jochim Fueßi trükikojas.

Nii isa Brockmanni kui ka tema abikaasa matusetalituse läbi viinud Güstrow'2 superintendent Lucas Bacmeister noorem (1570-1638, ka Lukas Backmeister, Bacmeisterus) on saksa kirikuloos tuntud kui luterluse pooldaja ja kirikulaulude autor (Bautz 1990: 329). Güstrow' osahertsogkonna ${ }^{3}$ koosseisu kuulus Schwaani linn, mille koguduse ja kahe abikoguduse pastor oli isa Brockmann, nii et superintendent Bacmeister oli isa Brockmanni otsene ülemus. Ülemus ja alluv said omavahel ilmselt hästi läbi. Margareta Scheffteri leinajutluses nimetab Bacmeister, et kui isa Brockmann palus tal osutada trööstiks austav teene ja pidada viimse lugupidamisavaldusena kadunud abikaasale leinajutlus, soostus ta meeleldi, sest ka „selles asjas tahan oma väga hea sõbra soovi rahuldada" (Bacmeister 1625: A II). Isa Brockmanni ärasaatmisel peetud jutluses nimetab superintendent koguni, et isa Brockmann pidas teda oma usaldusaluseks sõbraks (Bacmeister 1627: 41). Nagu allpool selgub, võis Bacmeisteri ja isa Brockmanni tutvus ulatuda noorusaegadesse.

\section{Margareta Scheffteri matusetrükis}

Margareta Scheffteri matuste puhul avaldatud kvartformaadis trükis (Bacmeister 1625) koosneb neljast neljalehelisest signatuuridega trükipoognast; trükises on kokku 32 lehekülge, kõigil neil on tekst. Kaasaegse tava kohaselt koosneb matusetrükis viiest osast: tiitellehest, pühendustest (käesoleval juhul $1 \mathrm{lk}$ ), leinajutlusest (18 ja pool lk), kadunu eluloost (6 lk) ja kadunule pühendatud leinaluuletustest (kuus ladinakeelset luuletust, $4 \mathrm{lk}$ ).

Jutluse juhatab sisse matusetalitust toimetava vaimuliku valitud piiblitsitaat ehk perikoop, mida jutluses seletatakse ja kadunuga seostatakse. Bacmeister oli valinud Margareta Scheffteri leinajutluse perikoobi Pauluse teisest kirjast Timoteusele (2Tm 4:18): „Küll Issand mind ka välja tõmbab kõigist kurjadest tegudest ja aitab oma taevasesse riiki. Temale olgu austus ajastuste ajastusteni! Aamen."

Genealoogia seisukohast on eriti huvitav matusetrükise neljas osa, kadunu elulugu, seal leiduvate elulooliste andmete tõttu. Huvi pakuvad veel nii pühendused kui ka leinaluuletused, kuna nende varal võib saada ettekujutuse kadunu ja tema pere lähemast tutvuskonnast ja sotsiaalsest positsioonist. ${ }^{5}$ Margareta Scheffteri

\footnotetext{
${ }^{2}$ Saksa $o w$-lõpulistes pärisnimedes jääb $w$ hääldamata, nii et Güstrow hääldatakse [güstro] või alamsaksapäraselt [jüstro].

${ }^{3}$ Mecklenburgi hertsogkonna jagamisel 1621. aastal moodustati selle idaosast MecklenburgGüstrow' osahertsogkond, mida valitses hertsog Johann Albrecht II. Ta resideeris Güstrow' linnas, 32 kilomeetrit Rostockist lõunas. Hertsog kutsus ametisse ja palkas Güstrow’ piiskopkonna superintendendi.

${ }^{4}$ Siin ja edaspidi on piiblitsitaadid 1968. aasta tõlke järgi (Piibel 1968).

${ }^{5}$ Teadaolevalt oli Fritz Roth esimene, kes süstemaatiliselt ja ulatuslikult kasutas matusetrükiseid genealoogia ja kultuuriajaloo allikana. Aastatel 1959-1980 avaldas ta Saksa aladel ajavahemikus 1560-1750 elanud kümne tuhande isiku elulood, sh poeg Brockmanni vanemate (Roth 1970:
} 
eluloost saame teada, et ta oli ausast ja heast perest (sks Ehrlich vnd wol gebohren), astus heasse abiellu (sie woll geheuratet hat') ning suri hästi ja õndsana (woll vnnd selig gestorben) (Bacmeister 1625: C III, D). Bacmeister on leinajutluse üles ehitanud heade eluviisidega ristiinimese teemale. Peab märkima, et wohlgeboren kandis varauusajal tähendust 'kõrgest seisusest, sünnilt suursugune' ning seda kasutati mitte ainult alamaadlike, vaid üha enam ka esileküündivate kodanikuseisusest isikute kohta (vt Adelung 1801: 1596). Kodanikkonda võis kuuluda Margareta Scheffteri ema Margareta Leitke, kes pärines Güstrow'st. Isa Zacharias Scheffter kuulus seevastu vaimulikuseisusse. Ta oli Schwaani Pauluse koguduse õpetaja ning pärines Schwerinist (Willgeroth 1924: 241). Enne Schwaani asumist oli ta töötanud Güstrow' toomkooli konrektorina (Ziegra 1770: 475).

Margareta sündis Schwaanis 6. novembril 1570 (Bacmeister 1625: C III). Kaks aastat varem oli peres sündinud poeg, kes kandis isaga sama nime (Hoche 1890). Kui isa Scheffter 1585. aasta aprillis suri, määras tolleaegne hertsog Ulrich 19. detsembril 1586 tema ametijärglaseks Schwaani pastori kohale Hamburgist pärit magister Georg Arendi (ka Georgius Arendes, Willgeroth 1924: 241; Schlie 1901: 8), kes ühtlasi nais oma eelkäija tütre. Pulmad peeti 26. jaanuaril 1587, napilt kolm kuud pärast Margareta 17. sünnipäeva. Ligi üksteist aastat kestnud abielu õnnistati viie lapsega (ema surma ajal olid elus tütar Gertrudt Arend ja poeg magister Georg (ka Georgius) Arend). Margareta Scheffteri ja Georg Arendi abielu katkestas mehe surm. Mehe ametijärglaseks Schwaani pastori kohal sai 30-aastane magister Reiner Brockmann, kes võttis kõhklematult naiseks noore, hea kuulsusega lese. Nad abiellusid 6. novembril 1598 (Bacmeister 1625: C III), Margareta Scheffteri 28. sünnipäeval. Sedagi abielu iseloomustab Bacmeister positiivselt. Ta tõstab esile Margareta erilist armastust ja austust abikaasa vastu, keda ta usinalt põetas „tema sagedase kehanõrkuse puhul”. Margareta südameasjaks oli majapidamise eest hoolitsemine, et meest säästa ja lasta tal ametit pidada, õppida ja tervist hoida. (Bacmeister 1625: C III)

Margareta Scheffteri ja isa Brockmanni peres sündis kolm poega ja neli tütart, keda Bacmeisteri sõnutsi aitas Margareta hoolikalt ja usinalt kasvatada. Nii nagu isa suunas poegi kooliteed käima, nii harjutas ema tütreid majapidamistöid tegema. Kõik lapsed olid elus, kui nende ema maine teekond lõppes. Sel hetkel õppis vanim poeg Zacharias Brockmann Rostocki ülikoolis teoloogiat ${ }^{6}$, nooremad Dethlev ${ }^{7}$ ja Reiner aga Hamburgis oma ema venna (jres Oheimbs), magister (poeg) Zacharias Scheffteri juhitavas õppeasutuses. ${ }^{8}$ (Bacmeister 1625: C III) Tütarde nimesid ei

R 5354, R 5932), superintendent Lucas Bacmeister noorema (Roth 1972: R 6132) ja veel mõne käesolevas kirjutises mainitu omad. Matusetrükiste kasutamise kohta ajalooallikana vt Rudolf Lenzi ülevaadet (1975).

${ }^{6}$ Zacharias Brockmann (1600-1661, snd Schwaanis) immatrikuleeriti Rostocki ülikooli jaanuaris 1619. Ta oli isa Brockmanni järglane Schwaani pastorina (1626-1661). (Willgeroth 1924: 241; MPR: Wintersemester 1618/1619, nr 67 (16. IV 2018)).

${ }^{7}$ Dethlev Brockmann (snd 1603 Schwaanis) immatrikuleeriti Rostocki ülikooli märtsis 1622 (MPR: Wintersemester 1621/1622, nr 33 (16. IV 2018)).

${ }^{8}$ 1613. aastal rajatud Hamburgi akadeemiline gümnaasium oli vaheaste 1529. aastal Johannes Bugenhageni asutatud Johanneumi õpetlaskooli ja ülikooli vahel, mistõttu rangelt luterlikuks peetud kooli õppekavas olid tähtsal kohal ladina ja kreeka keel (Sillem 1891: II, VII). 
nimetata, aga isa Brockmanni matusetrükisest selgub, et vanima tütre nimi oli Ilse (Bacmeister 1627: 41), usutavasti isa Brockmanni ema Ilse Kulrabe järgi.

1624/1625. aasta talvel jäi Margareta Scheffter nii ägedalt haigeks, et abikaasa ja lapsed tundsid tema pärast tõsist muret. Haige lohutas neid, kuid ennustas, et temaga läheb nagu ta oma emaga, kes oli surnud Maarja sündimise päeva (ussimaarjapäeva, 8. septembri) paiku. „Kui ma siis haigestun peahaigusesse, siis mind teie jaoks kauaks ei ole”, olevat ta öelnud. Ennustus läks täide: teisipäeval, 2. septembril tabas Margareta Scheffterit äge peahaigus. Ta suutis end järgnevaks päevaks nii palju koguda, et võis minna kirikusse paluma pattude andeksandmist. Üha süveneva haiguse tõttu luhtus lootus pühapäeval koos lähedastega armulaual käia, sellest sai ta osa kodus. Sealsamas suikus ta esmaspäeval, 8. septembril surmaunele „pehmelt ja õndsana Issandas Jeesuses Kristuses". (Bacmeister 1625: D)

\section{Isa Brockmanni matusetrükis}

Isa Brockmannile pühendatud matusetrükis (Bacmeister 1627) on abikaasa omast pooleteise trükipoogna võrra mahukam - 44 nummerdatud lehekülge, tiitellehe tagakülg on tekstita. Lehekülgede nummerduses on kaks viga: jutluseosas on nr 20 asemel trükitud 16 ja eluloo alguslehekülg kannab numbrit 33, kuigi see peaks olema 34. Lisaks lehekülgede nummerdusele on trükise poognatel veel tavapärased signatuurid. Tiitellehelt selgub, et brošüür trükiti kadunu laste soovil 1627. aastal, pool aastat pärast matuseid.

Erinevalt abikaasa matusetrükisest ei järgne isa Brockmanni omas tiitellehele ühtegi pühendust, vaid kohe jutlus, mis hõlmab 31 lehekülge. Bacmeisteri jutlus lähtus 27. Taaveti laulu 8., 9. ja 10. salmist: „Sinu sõna on see, mida mu süda ütleb: „Otsige mu palet!” Siis ma otsin, Jehoova, sinu palet! Ära peida oma palet minu eest, ära tõuka enesest vihas oma sulast! Sina olid mu abi, ära lükka mind ära, ja ära hülga mind, mu pääste Jumal! Sest mu isa ja ema hülgasid mind, aga Jehoova koristab mind!" Pühakirjakoht oli sobivalt valitud, sest isa Brockmanni surmaga jäid vanemateta nii poeg Brockmann kui ka tema kaks venda, neli õde ning poolõde ja -vend.

Jutlusele järgneb üheksal leheküljel kadunu elulugu. Sellest selgub, et isa Brockmann oli 1568. aastal sündinud Paderborni vürstpiiskopkonda kuuluvas Steinheimi linnas (Bacmeister 1627: [34]), kus tema isa Jürgen Brockman oli olnud 27 aastat linnapea (Bacmeister 1627: 35). Ema Ilse Kulrabe kuulus kohalikku kõrgemasse seltskonda (Bacmeister 1627: 35). Kooliteed alustas Reiner sünnilinna koolides, kuid kuna katoliiklik munk Johan von Vense tegi sel ajal Steinheimis ägedat usukihutustööd, eriti noorsoo hulgas, otsustasid vanemad poja „papistlikust ebajumalakummardamisest” päästa ja saatsid ta tol ajal Westfalenis hästi tuntud Lemgo linnakooli, et ta saaks "aluse vagaduse ja hea kirjanduse õpingutes” (Bacmeister 1627: 35). Seejärel siirdus ta Braunschweigi, kuna sealses koolis tegutses kõrgesti õpetatud mehena kuulsaks saanud Nicodemus Frischlin (1547-1590). Sinna jäi Reiner kolmeks aastaks (Bacmeister 1627: 36). Päris nii kaua ei võinud ta Frischlini õpetusest osa saada, sest too töötas Braunschweigi koolis õpetajana üpris lühikest aega, 
1588. aasta märtsist 1589. aasta sügiseni (Scherer 1878: 98). Brockmanni edasine elutee viis teda Lübecki, kus ta töötas seitse aastat raehärra Heinrich Wedenhoffi (ka Hinrich Wedemhof) laste koduõpetajana (Bacmeister 1627: 36). Pärast Wedenhoffi surma (1589) abiellus tema lesk Anna Horstmann Rostocki ülikooli juuraprofessori Jabob Bordingiga ${ }^{9}$ (Dittmer 1859: 93), kusjuures isa Brockmann jätkas senises ametis, pälvides suurt lugupidamist (Bacmeister 1627: 36). On usutav, et isa Brockmann tutvus Bordingi kaudu oma tulevase ülemuse Bacmeisteriga, sest Bordingi vanem õde Johanna (1544-1584) oli Bacmeisteri ema (Willgeroth 1925b: 1415). Isa Brockmanni varasem tutvus Jakob Bordingiga võis ka olla (lisa)põhjus, miks toetas Bording tugevasti isa Brockmanni nimetamist Schwaani kirikuõpetajaks.

Bordingi pere koduõpetaja ametist loobus isa Brockmann haridustee jätkamiseks (Bacmeister 1627: 36), esmalt Helmstedti ülikoolis (immatrikuleeriti 31. märtsil 1595 nime all Reinerus Brockmannus Steinheimius (Zimmermann 1926: 116)) ning seejärel Rostockis (septembris 1596, MPR: Sommersemester 1596, nr 85 (15. XI 2016)). Mõlemas ülikoolis õnnestus tal superintendent Bacmeisteri sõnutsi võita professorite poolehoid. Helmstedtis protežeeris teda eriti ajalooprofessor Reiner Reineccius. ${ }^{10}$ Rostockis toetasid teda rae palgatud ${ }^{11}$ teoloogiaprofessorid Valentin Schacht ${ }^{12}$ ja David Lobeck ${ }^{13}$, kellega ta olevat iga päev suhelnud ja neilt otsekui Paulus Gamaalieli jalge ees istudes ${ }^{14}$ teoloogiast palju õppinud ja aru saanud; Schacht võttis Brockmanni isegi oma majja laste koduõpetajaks. Kui Schwaani kirikuõpetaja magister (isa) Georg Arend suri, nimetati tema järeltulijaks Reiner Brockmann, keda kantsler Jakob Bording ja Rostocki teoloogid Schacht ja Lobeck olid väsimatu eestkostmisega teiste kandidaatide asemel toetanud. Ametisse astus Brockmann 1598. aasta jõulude eel ja nais oma eelkäija lese, Margareta Scheffteri, kelle lapsi eelmisest abielust ta olevat kohelnud oma lihaste lastena. (Bacmeister 1627: 36-38)

\footnotetext{
${ }_{9}^{9}$ Bording (1547-1616) oli selles ametis aastatel 1574-1598. Ta oli ka Mecklenburgi hertsogi kantsler (1586-1589) ja hiljem Lübecki linnapea (1600-1616) (Muther 1876).

${ }^{10}$ Reiner Reineccius (ka Reinhard Reyneke, 1541-1595), Helmstedti ülikooli ajalooprofessor (1582-1595), oli sündinud Steinheimi linnas nagu ka isa Brockmann. On aimatav nende isade ammune tutvus, sest Reinecciuse isa ja vanaisa olid sealse rae liikmed (Zimmermann 1889: 17-18), Brockmanni isa aga linnapea.

${ }^{11}$ Rostocki ülikoolil oli kahepoolne patronaat: linna magistraat palkas kaks teoloogia ja ühe õigusteaduse professori, teised professorid võttis tööle vürst, antud ajal hertsog (Tholuck 1854: 100).

${ }^{12}$ Valentin Schacht (1540-1607) sai professoriks aastal 1569, oli ühtlasi Püha Jakobi koguduse pastor (Bacmeister 1607: C; Kaufmann 1997: 100, 148). Ta oli sündinud Stargardis Pommeris (nüüdses Poolas), õppis algul Magdeburgis (Bacmeister 1607: B III), 1560. aasta mais astus Rostocki ülikooli (MPR: Wintersemester 1559/1560, nr 64 (15. XI 2016)), kus promoveeriti 1563. aasta 14. oktoobril vabade kunstide magistriks, misjärel hakkas loenguid pidama (Bacmeister 1607: B III; MPR: Philosophische Fakultät, Sommersemester 1563, nr 4 (15. XI 2016)).

${ }^{13}$ David Lobeck (ka Lobech, Lobechius, 1560-1603) sai professoriks 1594. aastal. Ta oli sündinud Elbe alamjooksul asuvas Land Hadelni ringkonnas, lõpetas Rostocki ülikooli kunstide magistrina 1583 ning sai sealsamas teoloogiadoktoriks 1594. Enne professoriks saamist oli ta töötanud Rostockis 1589-1591 Püha Peetruse ning seejärel Püha Jakobi koguduse pastorina. Lobeck oli Valentin Schachti väimees (CPR: Lobeck, David (15. XI 2016)) ja suri katku (Ziegra 1770: 544).

${ }^{14}$ Viide Apostlite tegudele Uues Testamendis, Ap 22: 3.
} 
Isa Brockmann olevat olnud rahumeelne inimene, kes ei seganud ennast võõrastesse asjadesse, vaid oli usklikele eeskujuks sõnas, elus, armastuses, vaimus, usus ja vooruslikkuses. Kahekümne kahe aasta vältel, mil Lucas Bacmeister oli Güstrow’ superintendendina töötanud, polevat ta kuulnud ainsatki kaebust pastor Brockmanni kohta. Kogu kihelkonnas oli üldteada, kui truult ta laupäeviti kiriku pihitoolis istus ning pühapäeva hommikuti nii suvel kui ka talvel kellaajast täpselt kinni pidades Wigendorffi ${ }^{15}$ abikirikus jutlustas, et seejärel jõuda õigeks ajaks tagasi Schwaani. Kirikuraamatut olevat ta Schwaanis, Grenzis ja Wigendorffis eriliselt suure hoolega pidanud. (Bacmeister 1627: 38-39)

Suure majapidamise eest hoolitses proua, nii et isa Brockmanni võidi ikka leida raamatute taga istumas. Abikaasa surm mõjus talle aga nii rängalt, et kehaliselt niigi nõrk mees hakkas kidunema. Majapidamistööd võttis üle küll vanem tütar, kuid isa Brockmanni südamekurbus süvenes, kuni ta jäi voodihaigeks. Ta olevat tahtnud veel superintendent Bacmeisterile kui oma usaldusalusele sõbrale kirjutada, kuidas toimida, kui ta ise ei jaksa enam laste eest hoolitseda, aga surm jõudis ette. (Bacmeister 1627: 39-42)

Isa Brockmanni surmakuupäeva ümber valitseb segadus. Matusetrükise järelehüüde lõpus on toodud kuupäev 23. juuli 1626 (Bacmeister 1627: 42). Sama kuupäeva mainib ka Gadebusch (1777: 128). Selle õigsuses on põhjust kahelda. Matusetrükise järelehüüdes seisab: „Ja on siis see õnnis mees [s.o isa Brockmann] möödunud jaaniööl 23. juulil õhtul kella 11 ja 12 vahel õndsalt Issandas uinunud 58 aasta vanuses", tiitellehel on aga väidetud, et matusetalitus toimus 27. juunil 1626. Jaaniöö on teatavasti öö vastu 24. juunit. Võime niisiis olla kindlad, et isa Brockmanni surmakuupäev oli 23. juuni 1626. Sama kuupäeva mainib ka Fritz Roth (1970: R 5354).

Matusetrükise lõpus on pealkirja „Threnodiæ” all kaks üheleheküljelist kreekakeelset leinaluuletust. Esimese luuletuse autor on Marcus Gerkenius, Megap [olitanus] 'mecklenburglane', teise oma Reinerus Broclmannus [sic!'] defuncti filius 'kadunu poeg. Gerken oli kantud Rostocki ülikooli matriklisse 1624. aasta mais ja tema nime taha märgiti Wismariensis Megapolitanus (MPR: Sommersemester 1624, nr 15 (15. XI 2016)), st Wismarist pärit. Usutavasti on ta seesama Markus Gerken, kes Mecklenburgi hingekarjaste matrikli andmeil 22. augustil 1630 ordineeriti Groß Poserini koguduse pastoriks ja kes põgenes 1638. aastal Güstrow’sse, kus ilmselt suri (Willgeroth 1924: 453-454). Tema isa kandis sama nime ning oli olnud Biendorfi koguduse pastor (Willgeroth 1924: 39; 453-454). Muid andmeid pole õnnestunud Gerkeni kohta leida. Isa Brockmannile pühendatud matusetrükises avaldatud kreekakeelne luuletus jäi oletatavasti tema ainsaks trükitööks, sest ühtki teist teost ei ole tema nime all saksa keeleruumi XVII sajandi trükiste andmebaasis märgitud (VD17: Gerkenius, Marcus (11. V 2020)). Pole ka teada ühtegi tema surma puhul avaldatud saksakeelset matusetrükist (GESA (11. V 2020)).

Gerken oli usutavasti poeg Brockmanni vanemate vendade, Zacharias ja Dethlev Brockmanni ülikoolikaaslane. Sellele viitavad nende immatrikuleerimisajad: Zachariasel aprill 1619, Dethlevil märts 1622 ning Gerkenil mai 1624. Kuigi Reinholdus

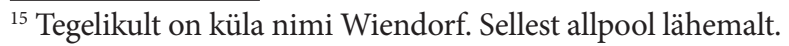


Brockman Suanensis ehk poeg Brockmann oli immatrikuleerunud Gerkenist veidi varem, augustis 1623 (MPR: Sommersemester 1623, nr 187 (15. XI 2016)), on matriklisse märkimise aeg tema puhul ilmselt puht formaalne ega pruugi tähendada ülikooliõpingute algust. Seda näitab matriklis tema sissekande juurde tehtud rist, millega tähistati neid, kes alaealisuse tõttu polnud vannet andnud. Poeg Brockmann oligi siis vaid 14-aastane ja õppis veel Hamburgi akadeemilises gümnaasiumis, kuhu ta viidi Hamburgi õpetlaskoolist üle rektor Joachim Jungiuse soovitusel (Sandhagen 1648: D), järelikult pärast oma onu, varasema rektori Zacharias Scheffteri surma 5. märtsil 1626 (Hoche 1890: 688; Sillem 1891: 16, märkus 1). Hamburgist Rostocki kolis poeg Brockmann 1630. aasta avakuudel (Viiding 2015: 777) ja alustas ilmselt alles siis ülikooliõpinguid. Samas ei saa välistada võimalust, et Gerken ja poeg Brockmann võisid tutvuda Wismari linnakoolis. Poeg Brockmanni kohta teame, et ta läks pärast Rostocki linnakoolist lahkumist ja enne Hamburgi kooli siirdumist Wismari kooli õppima (Sandhagen 1648: D). Gerkeni õppimine sünnilinna koolis jääb seeeest pelgalt oletuseks.

\section{Leinajate ring}

Margareta Scheffteri matusetrükise tiitellehe tagaküljel on leinajutluse pidanud superintendent Bacmeisteri pühendus kadunu elus olevatele lähedastele: abikaasale, vennale magister Zacharias Scheffterile, tütre abikaasale magister Rudolph von Ankumile, pojale magister Georg Arendile ning, nimesid nimetamata, kõigile teistele poegadele ja tütardele. Kõik pühenduses nimetsi loetletud on mehed.

Tütre (esimesest abielust) Gertrudt Arendi nimi selgub elulookirjeldusest, kus superintendent iseloomustab teda auväärse ja kõrgesti õpetatud härra magister Rudolph von Ankumi, Malchow' kirikuõpetaja kiiduväärse, voorusliku ja kõrgesti armastatud majaemandana (Bacmeister 1625: C III). Rudolph von Ankum (ka Anckum) oli pärit Osnabrückist (Willgeroth 1924: 414). ${ }^{16}$ Tema sünniaastat pole õnnestunud kindlaks teha, aga 1612. aastal asus ta ametisse Schwaani koguduse kantori ehk orelimängija ja kirikukoori juhina. 1620. aasta kevadel sai temast sealsamas diakon (Willgeroth 1924: 414). Tema pikaajaline otsene ülemus oli niisiis koguduse kirikuõpetaja isa Brockmann.

Margareta Scheffteri vend Zacharias Scheffter oli magistrikraadiga. Tema sünniaastaks pakutakse 1568 (Hoche 1890: 688; VD17: Scheffter, Zacharias (15. XI 2016)). Scheffter oli varem töötanud Ülem-Frangimaal asuva Coburgi vürstliku gümnaasiumi rektorina, kuid oli nüüd „Hamburgi gümnaasiumi ja [õpetlas]kooli teenekas rektor"17 (Bacmeister 1625: C III; vt ka Calmberg 1829: 91-92).

Viimane pühenduses nimetatu oli Margareta Scheffteri poeg esimesest abielust, magister Georg Arend (Bacmeister 1625: C III). Ta oli sündinud teadmata ajal Schwaanis ning oli saanud Wareni linna Püha Jüri koguduse hingekarjaseks

\footnotetext{
${ }^{16}$ Perekonnanime järgi otsustades pärines suguvõsa Osnabrückist põhja pool asuvast Ankumi väikelinnast.

${ }^{17}$ Nende õppeasutuste kohta vt märkust 8.
} 
1624. aastal (Willgeroth 1925a: 734). Ta suri 21. mail 1638 (Willgeroth 1925a: 735), usutavasti katku. ${ }^{18}$

Peale sugulus- või hõimlussuhete kaudu Margareta Scheffteriga seotud isikute kuuluvad tema leinajate ringi veel matusetrükise kuue ladinakeelse leinaluuletuse autorid. Need on trükises leiduvate luuletuste järjestuses Rostocki ülikooli korraline vürstlik teoloogiaprofessor Johann Tarnow, Rostocki Püha Nikolai koguduse pastor Johannes Goldstein, Rostocki linnakooli rektor magister Heinrich Vulpius ning Rostocki ülikooli teoloogiaüliõpilased Johannes Tarnovius, Heinrich Steltman ja Johannes Bannehr.

Leinaluuletuste autoritest kahtlemata nimekaim, vähemalt saksa kultuuriruumis, on professor Johann Tarnow (ka Johannes Tarnovius, 1586-1629), kes oli luteriusu teoloogina kõrgelt hinnatud eksegeet (Schmaltz 1936: 199) ning viljakas kirjamees. ${ }^{19}$ Tarnow' leinaluuletus on pikim. Tarnow oli sündinud Grevesmühleni linnas Mecklenburgis pastor Hermann Tarnow' pojana, õppis kõigepealt Katharineumi koolis Lübeckis (Lumpe 1996: 504) ja astus aprillis 1604 Rostocki ülikooli usuteadust õppima (MPR: Wintersemester 1603/1604, nr 41 (16. VIII 2019)). 1613. aastal alustatud õpireisi kestel omandas ta 1614. aastal Straßburgis magistrikraadi (Lumpe 1996: 504), mispeale temast sai Rostocki ülikoolis Lucas Bacmeisteri järglane teoloogiaprofessori kohal (Mahlmann 1996: 529). 15. aprillil 1619 promoveerus Tarnow Rostocki ülikoolis teoloogiadoktoriks (MPR: Theologische Fakultät, Wintersemester 1618/1619, nr 1 (16. VIII 2019)) ja nimetati korraliseks vürstlikuks teoloogiaprofessoriks (Mahlmann 1996: 529).

Järgmise luuletuse autor Johann[es] Goldstein oli sündinud 1560. aastal Westfaleni linnas Rüthenis (Willgeroth 1925b: 1428), tema isa suri vaid viis nädalat pärast poja sündi, nii et teda kasvatas ja toitis ema väga vaevaliselt. Algul õppis Goldstein kodumaal ehk Westfalenis, kuid õpinguteks kaugemal asuvates õppeasutustes pidi noormees ise linnakodanike poegade koduõpetajana elatist teenima. (Stein 1635: i) Suur püüd hariduse poole viis Goldsteini kõigepealt Göttingeni, Lübecki ja Wismari ning lõpuks Rostocki ülikooli, kuhu ta immatrikuleeriti 22-aastaselt oktoobris 1582 nime all Iohannes Chrysolitus, ${ }^{20}$ Rudenses ex Westphalia (Stein 1635: ij; MPR: Sommersemester 1582, nr 131 (26. VIII 2019)). 1594. aastal promoveeriti Goldstein Rostocki ülikooli magistriks (MPR: Philosophische Fakultät, Wintersemester 1593/1594, nr 3 (26. VIII 2019)) ja ta töötas seejärel Wismari linnakooli konrektorina, kuni temast järgmise aasta 25. veebruaril sai Rostocki Püha Nikolai koguduse pastor (Willgeroth 1925b: 1428). Sellel ametikohal töötas ta veel Margareta Scheffteri surma ja matuste ajal, ehkki matusetrükises pole tema ametit märgitud.

\footnotetext{
${ }^{18}$ 1638. aastal surid ka näiteks Lucas Bacmeister (Willgeroth 1924: 248), Rudolph von Ankum (Willgeroth 1924: 414-415) ja poeg Marcus Gerken (Willgeroth 1924: 454). Kahe esimese elulugudes on surma põhjuseks märgitud katk.

${ }^{19} \mathrm{VD} 17$ kataloogis on ta registreeritud 136 trükise autorina, neist 98 ainuautorina, kusjuures mõned nimetused on kordustrükid (VD17: Tarnow, Johann (16. VIII 2019)).

${ }^{20}$ Nagu paljud humanismiajastu õpetlased kasutas ka Goldstein oma perekonnanime hellenisee-

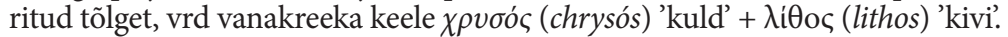


Kolmanda luuletuse autor on Rostocki linnakooli rektor magister Henricus Vulpius (ka Heinrich Voss ${ }^{21}$ ), tulevane Tallinna gümnaasiumi teoloogiaprofessor ja rektor. Nagu selgub luuletuse autorinime järel olevast fraasist Lemg[oviensis] Westph[aliae], oli Vulpius pärit Lemgo linnast ja seega vestfaallane nagu Johann Goldsteingi. Lemgoga oli seotud ka isa Brockmann, kes oli seal õppinud. Vulpiuse sünniaasta on teadmata. 30. märtsil 1612 kanti ta Helmstedti ülikooli matriklisse (Zimmermann 1926: 220), veebruaris 1614 Rostocki ülikooli omasse (MPR: Wintersemester 1613/1614, nr 44 (28. VIII 2019)). 2. mail 1617 promoveeriti ta nime all Hinricus Vulpius Westphalus Rostocki ülikooli filosoofiateaduskonnas magistriks (MPR: Philosophische Fakultät, Wintersemester 1616/1617, nr 15 (28. VIII 2019)). Järgmisel aastal nimetati ta Rostocki linnakooli konrektoriks ning 3. mail 1620 rektoriks. Selles ametis oli ta kuni Tallinnasse lahkumiseni (Becker 1930: 115). Vulpiuse rektoriks valimisel olid omad põhjused. Juba 1610. aasta paiku oli linnakool pea täielikult alla käinud. Vanema klassi õpilased rikkusid distsipliini, õpetajad ei saanud enam piisavalt palka, jätsid õppetöö hooletusse ja otsisid kõrvalteenistust tunduvalt tulusamate erakoolide pidamisest, mille tõttu linnakooli õpilaste arv vähenes. Korra jalule seadmiseks vallandati mitmed õpetajad ja rektor. Vulpius suutis kooli taas tõusuteele juhtida, saavutades sellega linnas suure populaarsuse. Kui ta sai kutse minna Tallinna gümnaasiumisse, püüdis raad teda alguses isegi tagasi hoida. (Neumann 1930: 28-29; Schmaltz 1936: 202)

Neljanda luuletuse autoriks märgitud Johannes Tarnovius S.S. [= Sanctissimae] Theologice Studiosus 'kõige pühama/puhtama teoloogia üliõpilane' isiku väljaselgitamine osutus keeruliseks. Margareta Scheffteri matusetrükisest pole luuletuse autori kohta muud leida, kui et ta oli usuteaduse üliõpilane, eeldatavasti Rostocki ülikoolis, kus oli aga XVII sajandi esimesel veerandil kolm Johann Tarnow' nimelist isikut. Neist esimene, professor Johann Tarnow ei tule antud seoses kõne alla, seda enam, et samas trükises on tema sulest esimene luuletus.

1612. aasta juunis kanti ülikooli matriklisse teine Johann Tarnow: Johannes Tarnouius Rostochiensis, rectoris pro tempore filius 'praeguse rektori [st Paul Tarnow'] poeg. Nagu selgub juurdekirjutusest, andis rostocklane vande alles oktoobris 1618, ilmselt alaealisuse tõttu. (MPR: Sommersemester 1612, nr 43 (2. IX 2019)) Tema edasise elukäigu kohta pole õnnestunud midagi leida, kuid on võimalik, et Kopenhaageni ülikooli matriklisse 1621. aasta 24. aprillil kantud Joh. Ternouius Rostochiensis Rostochio (Birket-Smith 1890: 50) on sama isik. Suguvõsauurija Ib Keld Jenseni andmeil elas Kopenhaagenis Paul Tarnow' hõimlane (Ib K. Jenseni koduleht: Tarnov, Johannes (9. VI 2020)), nii et side Kopenhaageniga oli Johann Pauli pojal Tarnow'l olemas.

Kolmas Johann Tarnow immatrikuleeriti Rostocki ülikooli 1619. aasta juunis nime all Ioannes Tarnovius Grevismolens[is] (MPR: Sommersemester 1619, nr 88 (2. IX 2019), vrd Matrikel der Universität Rostock 1419-1760: [640] 638). ${ }^{22}$

\footnotetext{
${ }^{21}$ Alamsaksa keeles tähendab voss rebast, vrd ülemsaksa Fuchs; ladina keeles on rebane vulpes, omastav vulpis.

${ }^{22}$ Rostocki ülikooli matrikliportaalis on sissekande all toodud ristviited (tulevase professori) Johann Tarnow' immatrikulatsioonile 1603. aastal ja doktoriks promoveerimisele 1618. aastal,
} 
Pole võimalik otsustada, kumb neist Johann Tarnow'dest, rostocklane või grevesmühlenlane, võiks olla Margareta Scheffteri matusetrükises ilmunud luuletuse autor.

Kahe viimase luuletuse autorid on Henricus Steltman Susat[ensis] Westphal[ioe] 'vestfaallane Soestist' ja Johannes Bannerus Malchowi[ensis]-Megap[olitanus] 'malchowlane Mecklenburgist'. Mõlemad on luuletuse kirjutamise ajal üliõpilased, nagu ka Johann Tarnow. Heinrich Steltman kanti Rostocki ülikooli matriklisse aprillis 1623 ja Johannes Bannehr mais 1624 (MPR: Wintersemester 1622/1623, nr 80, Sommersemester 1624, nr 45 (29. VIII 2019)). Nende immatrikulatsiooni ajad on lähedased Dethlev Brockmanni omaga (märts 1622), mis viib mõtteni, et nad võisid olla tema ülikoolikaaslased. Peale Rostocki ülikooli astumise aja pole Steltmani ja Bannehri kohta õnnestunud muid eluloolisi andmeid leida.

Margareta Scheffteri matusetrükises on niisiis nimepidi teada olevaid leinajaid mitu. Selle poolest erineb tema matusetrükis abikaasa omast, kus nimetsi mainitud leinalisi on kasinasti ja leinaluuletusi vaid kaks. Isa Brockmanni matusetrükise tiitellehel on toodud ära kolme isiku nimed (kadunu, jutluse pidaja Bacmeisteri ja trükkal Jochim Fueßi omad), jutluses esineb vaid kadunu enda nimi. Sama trükise eluloolises osas nimetab superintendent Bacmeister isa Brockmanni leinajatena võõraslapsi, magister (poeg) Georg Arendit ja Gertrud Arendit (Bacmeister 1627: 38), samuti kadunu vanimat tütart Ilset ja Schwaani naaberkoguduse Hohen Sprenzi koguduse pastorit, kellega isa Brockmann oli vahetult enne oma surma arutanud, kuidas tema lastega jääb (Bacmeister 1627: 41). Pastori nime Bacmeister ei maini, küllap oli see kõigile asjaosalistele niigi teada. Mecklenburgi vaimulike leksikonist selgub, et Hohen Sprenzi pastor oli sel ajal Peter Plaggenmeier ${ }^{23}$ (Willgeroth 1924: 403).

\section{Side Rostocki ülikooli ringkondadega}

Nagu näeme, on kõik Margareta Scheffteri matusetrükises pühendusluuletusega esinenud isikud seotud Rostocki ülikooliga. See kehtib mitte ainult professor Johann Tarnow’ ja kolme üliõpilase, vaid ka linnakooli rektori Henricus Vulpiuse ja Johann Goldsteini kohta, kes olid Rostocki ülikooli kasvandikud (kuigi kumbki ei töötanud Margareta Scheffteri matuste ajal ülikoolis), Goldstein oli sealsamas omandanud ka magistrikraadi.

Margareta Scheffteri leinajate seotus Rostocki ülikooliga pole tähtsusetu. Nagu väidab Karl Schmaltz, olid sealsed usuteadlased ainult piiratud ulatuses läinud kaasa luterluse mõne kaasaegse suundumusega. Endiselt pooldasid rostocklased pühakirja rangelt teaduslikul alusel kontekstisidusat uurimist ja seletamist, st reeglikohast

samuti kasutaja Silvia Engeli kommentaar, milles on professor Johann Tarnow' eluandmed (http://purl.uni-rostock.de/matrikel/100024593 (14. VI 2020)). Sellest võib jääda mulje, et professor Johann Tarnow ja 1619. aastal immatrikuleerunud Ioannes Tarnovius Grevismolensis võiksid olla üks ja sama isik. Samastus on kindlasti ekslik, sest pole usutav, et Johann Tarnow 1619. aastal immatrikuleeruks ülikooli, mille professor ta oli aastast 1614.

${ }^{23}$ Peter Plaggenmeier (ka Petrus Plaggemeier, u 1584 Rostock - 1638 Hohen Sprenz) astus Rostocki ülikooli aprillis 1603, kutsuti Hohen Sprenzi pastori kohale 19. märtsil 1611 (Willgeroth 1924: 403; MPR: Wintersemester 1602/1603, nr 51 (16. VIII 2019)). 
eksegeesi, mis mujal kippus asenduma üksikute piiblitsitaatide dogmaatilis-pragmaatilise käsitlemisega, mille eesmärk oli lükata tagasi „agressiivse kalvinismi ja taasärganud ning samuti pealetungiva katoliku kiriku teoloogia”. (Schmaltz 1936: 198) Nii valitseski Rostocki ülikoolis alates XVI sajandi lõpust õhkkond, mis veel 1620. aastatel lubas küsimuse alla seada isegi oma kiriku autoriteete (Schmaltz 1936: 198, 201). Ilmekas näide sellest on Johann Tarnow’ teos „Piibliharjutused” („Exercitationes Biblicae”, 1619), milles autor ei hoidunud kritiseerimast mitme juhtiva luterliku teoloogi arvamusi ega isegi paari Martin Lutheri tõlgendust. See kutsus esile Wittenbergi, Leipzigi ja Jena teoloogide protesti. Tarnow avaldas 1621. aastal oma seisukohtade õigustamiseks uue teose, samal ajal kui tema onu Paul Tarnow, ${ }^{24}$ Rostocki ülikooli teoloogia esimese professuuri täitja, seega professor primarius ehk usuteaduskonna seenior, astus üles vennapoja kaitseks (Mahlmann 1996: 531-532; Schmaltz 1936: 199). Nii Paul Tarnow kui ka Johann Tarnow olid oma kirjatöödes mõjutatud Johann Arndti hingekosutusteostest ning jagasid, nagu Bacmeistergi, Arndti arvamust, et luterlik kirik vajab sisemist reformi (Leube 1924: 64-66, 87, 169, 1975: 69-70). Mõlemaid Tarnow'sid ongi arvatud pietismi eelkäijate hulka (Lumpe 1996: 505). Samasse ringkonda kuulusid veel eespool nimetatud juuraprofessor Jakob Bording, usuteaduse professor Valentin Schacht ja erakorraline usuteaduse professor David Lobeck (Schmaltz 1936: 198-199, 201), kes ühtlasi olid seotud isa Brockmanniga ja tema suhtes positiivselt meelestatud.

Kuna Rostocki ülikooli eelpietismile avatud õhkkonnas õppis poeg Brockmann, võis ta tunda teatud poolehoidu eelpietistlike ideede suhtes, nii nagu need avalduvad Johann Arndti hingekosutuslikes teostes „Tõelisest kristlusest” (,Von wahrem Christenthum”, 1605), „Neli raamatut tõelisest kristlusest” („Vier Bücher Von wahrem Christenthumb”, 1605-1610) ja „Paradiisiaiake” („Paradiesgärtlein”, 1612). Need erakordselt mõjukad teosed olid tõlgitud paljudesse Euroopa keeltesse. Sellise meelsusega võiski poeg Brockmann 1634. aasta mai lõpus Tallinnasse saabuda, olles võtnud vastu kutse tulla vastrajatud gümnaasiumi uueks kreeka keele professoriks.

Pietistlik mõttelõng viib edasi tema poja, Laiuse koguduse õpetaja ja Tartumaa Ülejõe praostkonna praosti Reiner Brockmanni juurde, kes alates 1680. aastatest oli kaastegev superintendent Johann Fischeri eestvõttel toimunud piiblitõlkimises ja kes võttis osa nii Liepa kui ka Pilistvere keelekonverentsist (Kõpp 1937: 107; Vahtre 2005: 224, 235). Kindlasti oli tal tulnud vastutada Pilistvere konverentsi korraldamise eest, kuna see toimus tema juhitud praostkonnas. Tema otsene ülemus superintendent Fischer oli teatavasti pietist, keda sidus kauane soe sõprus pietismi esileküündivamate esindajate hulka kuulunud Philipp Jakob Speneriga (Wallmann 1970: 52, joonealune märkus 59; Wieselgren 1964-1966: 56).

\footnotetext{
${ }^{24}$ Paul Tarnow (ka Paulus Tarnovius, 1562-1633) alustas Rostockis ülikooliõpinguid 1581 (Mahlmann 1996: 526), omandas magistrikraadi 1593 (MPR: Philosophische Fakultät, Sommersemester 1593, nr 3 (13. XI 2019)), nimetati 1604. aastal oma õpetaja David Chytraeuse järeltulijaks esimese teoloogiaprofessori kohal ja promoveerus teoloogiadoktoriks 1605 (MPR: Theologische Fakultät, Sommersemester 1605, nr 1 (13. XI 2019)). Rostocki ülikooli rektori ametisse astumise kõnes 23. aprillil 1624 kutsus ta üles reformima usulist vagadust ja luterlikku kirikut (Gummelt 2005; Mahlmann 1996: 534).
} 
Ka praost Reiner Brockmanni samanimelisel pojal (1677-1738) oli kokkupuuteid pietistlike ideedega ning ta polnud elu jooksul nende suhtes ilmselt sugugi tõrjuv. Esmatutvust pietistlike vaadetega võis ta ehk teha juba kodus isa käe all, aga Riia lütseumis ja Tartu ülikoolis õppides puutus ta lähedalt kokku pietistlikult meelestatud isikutega. Nende hulka kuulusid Riia lütseumi rektor Johann Uppendorp (ka Uppendorf; ametiaeg 1677-1698) ning Tartu ülikooli professor ja kolmekordne rektor Michael Dau (?-1710; ametiajad rektorina 1695, 1699-1700, 1702). Uppendorp oli juba varem Stockholmi saksa kooli rektorina ilmutanud poolehoidu Speneri vaadetele. Dau, keda Brockmann hiljem nimetas oma Tartu ülikooli õppejõududest tähtsaimaks, polnud küll usuteaduse, vaid teoreetilise filosoofia professor (ametiajad 1690-1691, 1694-1704), kuid oli oma tugevate usuliste huvide tõttu süüvinud usuteaduse küsimustesse ja sel alal ka avaldanud arvukalt töid. Ta oli väga lugupeetud nii kolleegide kui ka üliõpilaste seas. (Raag 2016: 876-877; vt ka Friedenthal 2019: 177-178) Põhjasõja ajal teenis Brockmann vaimulikuna algul Lohusuus, seejärel vaheldumisi oma isa pastoraadis Laiusel ja Rootsi sõjaväes. Kui Vene väed vallutasid Läänemereprovintsid, põgenes Brockmann oma perega Uusimaa kaudu Stockholmi. (Raag 2016: 879-885) 1712. aasta lõpust alates täitis Brockmann Norrköpingi saksa koguduse pastori kohta. Ta asutas kohaliku trükikoja ja ühtlasi juhtis seda tulemusrikkalt. Selle toodangu seas olid mitmed väljapaistvate eelpietistlike autorite tööd, alates Christian Scriveri ${ }^{25}$ kuueosalisest postillist „Hinge aare” („SeelenSchatz”, ilmus kahes trükis: 1724-1727 ja 1728-1731) ja lõpetades Johann Arndti neljaköitelise teosega „Tõelisest kristlusest” (ilmus 1732). Brockmanni tegevus on seda tähelepanuväärsem, et nii Rootsi keskvõim kui ka kiriku juhtkond suhtusid tol ajal pietistlikusse usulisse ärkamisse tõrjuvalt. See suhtumine tipnes 1726. aasta jaanuaris pietistide vastu suunatud kuninga määrusega (rts konventikelplakatet), mis keelas ära ja muutis karistatavaks koduste palvekoosolekute pidamise. Brockmanni tegevus näib ühtlasi välistavat võimaluse, et tema pietismilembus võis oleneda juhusest, olla tingitud üldisest ajavaimust või tema heast ärivaistust. (Raag 2016: 894) Nii tundub usutavana, et poolehoid eelpietismi ja pietismi ideedele on olnud omane neljale Reiner Brockmannile.

\section{Poeg Brockmanni luuletus isa surma puhul}

17-aastase poja Brockmanni luuletus isa matusetrükises on vanakreeka keeles 26-realine eleegilises distihhonis poees, millest esimene värss on heksameeter ja teine pentameeter (pilt 1). Minu palvel tõlkis dotsent Marianne Wifstrand Schiebe Uppsalast luuletuse lahkelt vanakreeka keelest rootsi keelde. Allpool järgneb minu vaba eestikeelne tõlge eelmainitud tõlkest.

\footnotetext{
${ }^{25}$ Temalgi oli seos Rostocki ülikooliga: ta immatrikuleeriti 1647. aasta oktoobris (MPR: Sommersemester 1647, nr 127 (28. XI 2019)).
} 


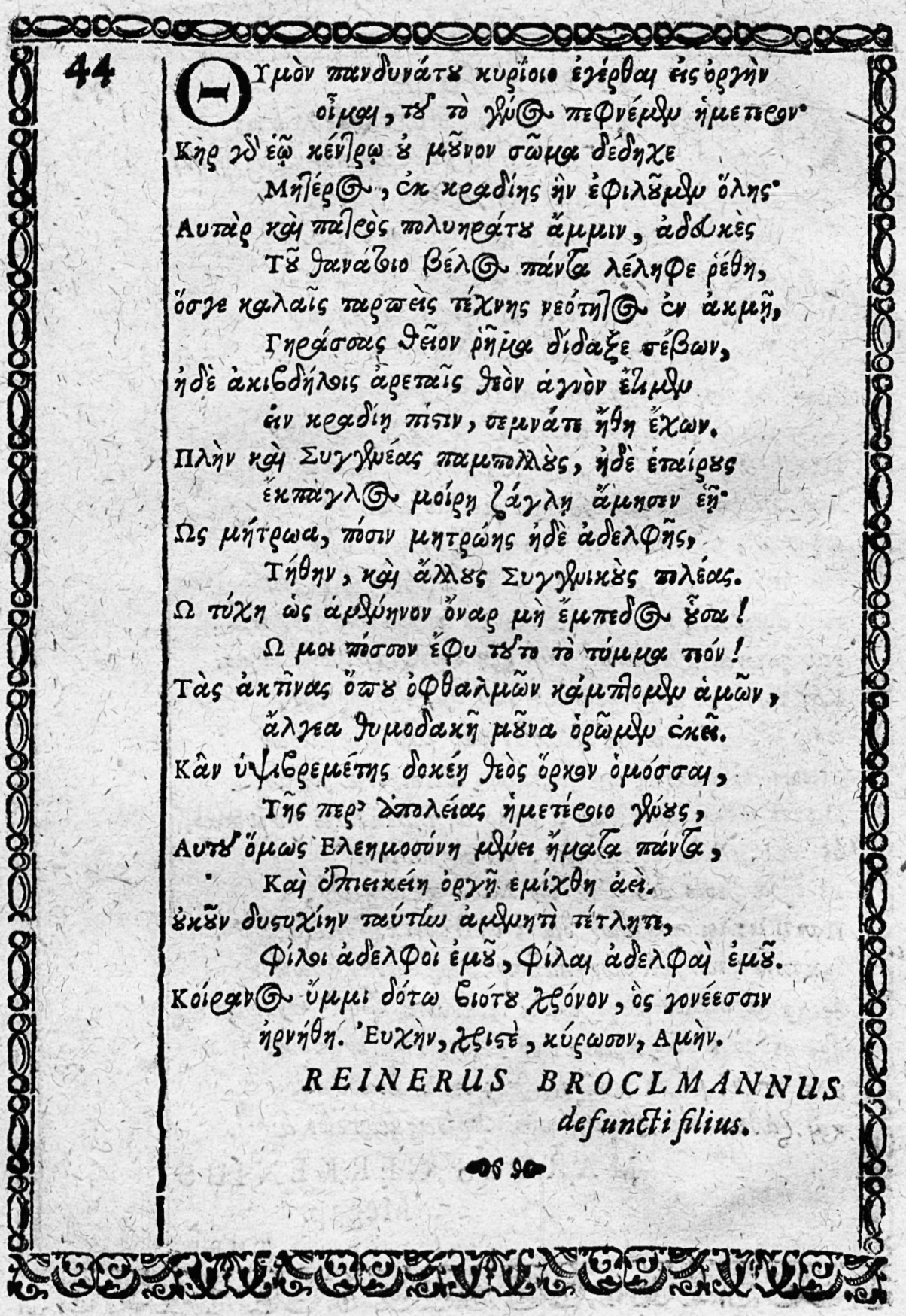

Pilt 1. Poeg Brockmanni luuletus isa surma puhul avaldatud trükises (Bacmeister 1627, Berliini riigiraamatukogu / Staatsbibliothek zu Berlin, Preußischer Kulturbesitz, Ee 710-187). 
[1-2] Usun, et kõigeväelisema Issanda meelt on vallanud raev meie suguvõsa hävitamiseks.

[3-4] Sest surmajumalanna on tabanud mitte ainult me kogu südamest armastatud ema ihu,

[5-6] vaid surma julm nool tabas ka me kõrgesti armastatud isa kõiki liikmeid,

[7-8] teda, kes pärast kunstide ilu nautimist nooruse õitsengu ajal oli vanas eas austusega kuulutanud jumalikku sõna,

[9-10] ja kandes oma südames usku ja siivsaid kombeid, avaldas tõeliste voorustega pühale jumalale austust.

[11-12] Aga ka hulga sugulasi ja sõpru lõikas saatus oma sirbiga,

[13-14] nagu mu onu, ja mu tädi abikaasat, vanaema ja paljusid teisi sugulasi.

[15-16] Oh, saatus, niisama heitlik nagu põgus unenägu! Ah, kui kõvasti on su löök mind tabanud!

[17-18] Kuhu me ka ei pööraks oma silmade sära, näeme seal vaid südantlõhestavaid piinasid.

[19-20] Aga kui ka jumal, kes taevalaotuses müristab, näib olevat vandunud, et hävitab me suguvõsa,

[21-22] jääb ikkagi tema igapäevane kaastunne ja raevuga on alati segunenud leebus.

[23-24] Kannatage seepärast mööduvat õnnetust välja, mu armsad vennad, mu armsad õed.

[25-26] Kinkigu Issand teile elupäevi, mida ta me vanematele keeldus andmast. Kristus, toeta seda palvet. Aamen.

Luuletuses on antiikmütoloogia põimunud kristlike kujutelmadega, mis tolleaegses juhuluules polnud sugugi haruldane nähtus. Juba algusridades toob autor kristlaste kõigeväelisema Issanda kõrvale surmajumalanna. Keda poeg Brockmann antiikmütoloogia surmajumalannadest silmas peab, kas näiteks Adrasteiat, Persephonet, Macariat, Atropost või kedagi teist, jäägu lahtiseks. Samas viib „surma julm nool”, millega surmajumalanna tabas „meie kogu südamest armastatud ema ihu”, tahtmatult mõtte Zeusi ja Leto tütrele ning Apolloni kaksikõele, jahi- ja loodusjumalannale Artemisele. Teda kujutatakse vahel noolt ja oda käes hoidvana ning ta võis, nagu märgib Theodor Schreiber (1884-1886: 576), oma nooltega anda tema soosingu võitnud tüdrukutele ja naistele valutu surma. Luuletust kirjutades võiski poeg Brockmann seda mõelda. Surmajumalanna puhul võib veel mõelda mõnele amatsoonile - nad polnud küll surmajumalannad, kuid võitlesid ka vibu ja nooltega.

Väide isa Brockmanni kohta, et ta nooruse õitsengu ajal nautis kunstide ilu (read 7-8), viitab arvatavasti kas kadunu õpinguajale Lemgos ja Braunschweigi linnakoolides ning Helmstedti ja Rostocki ülikoolis või hoopis ajale, mil ta töötas Lübeckis koduõpetajana.

Järgnevalt (read 13-14) loetleb luuletuse autor sugulasi, keda surm on ära viinud (arvatavasti üsna hiljuti): onu, tädi abikaasa ja vanaema. Onu on (poeg) Zacharias Scheffter, Hamburgi õpetlaskooli ja gümnaasiumi rektor, kelle maine teekond lõppes kümme kuud enne isa Brockmanni surma (Hoche 1890). Samuti lahkununa nime- 
tatud tädi abikaasa peaks olema autori ema õemees, kuid ei tema nime ega eluloolisi andmeid pole õnnestunud leida. Tuvastamata jääb ka mainitud vanaema isik. Võibolla on mõeldud Margareta Scheffteri ema Margareta Leitket või hoopis Margareta Scheffteri esimese abikaasa Georg Arendi ema- või isapoolset ema. Isa Brockmanni ema Ilse Kulrabe võib kõne alla tulla hiljuti lahkununa, sest Bacmeister kasutab tema kohta epiteeti selig 'õnnis; lahkunud' (Bacmeister 1627: 35), kuid sel juhul pidi ta surres olema umbes 75-76-aastane (oletatav sünniaasta 1550, vt GEDBAS: Kulrabe, Ilse (10. VI 2020)). On võimalik, et poeg Brockmann vihjab luuletuses veel (arvatava) õpingukaaslase Marcus Gerkeni isa surmale, kirjutades: „Aga ka hulga sugulasi ja sõpru lõikas saatus oma sirbiga." Mecklenburgi hingekarjaste matrikli andmeil oli Biendorfi pastor Markus Gerken surnud 1626. aasta alguses (Willgeroth 1924: 39), umbes pool aastat enne isa Brockmanni.

Lause „Kuhu me ka ei pööraks oma silmade sära, näeme seal vaid südantlõhestavaid piinasid" (read 17-18) näib viitavat rasketele ja masendavatele ning paljusid inimohvreid nõudnud oludele ajal, mil leidsid aset luuletuse kirjutamist ajendanud kurvad perekondlikud sündmused. Kolmekümneaastase sõja lahingud polnud küll veel otseselt Mecklenburgi puudutanud, sest Saksa-Rooma keisri ja Katoliikliku Liiga väed jõudsid sinna alles 1628. aasta suvel, aga hertsogkonna elanikke olid äsja tabanud muud hädad: katkuepideemia (1624), üleujutus (1625) ja nälg (1627) (Leube 1924: 66). Nii on mõistetavad luuletuse consolatio - kõigeväelisema Issanda kaastunne jääb iga päev ja tema raevuga on alati segunenud leebus (read 21-22) ning üleskutse elus olevatele möödunud õnnetusi välja kannatada (read 23-24).

Luuletuse autor on pikkinud teksti viiteid antiikautoritele, võib-olla ka kirikuisadele, aga nende väljatoomine, samuti luuletuse vormi ja sisu lähem kommenteerimine jäägu selleks pädeva uurija ülesandeks.

\section{Kus sündis juhuluuletaja Reiner Brockmann?}

Kui tutvuda poeg Brockmanni elu ja tegevust käsitleva kirjandusega, hakkab silma, et sünnikoha mainimisel on kuni viimase ajani valitsenud segadus. Üldiselt märgitakse tema sünnikohana Mecklenburgis asuvat Schwa(a)ni (Sandhagen 1648: D; Telschow 2000: 33; Saagpakk 2009: 51; TEA: 329; Klöker 2014: 542), kuid nii mõnigi kord mainitakse sünnikohana Schwa(a)n-Gränzdorfi (Siirak 1975: 52, 1995: 67; EE 2000: 40; Aarma 2007: 36). Samuti väidetakse, et tema isa, magister Reiner Brockmann, oli kirikuõpetaja Schwa(a)nis, Gränzdorfis ja Wi(e)gendorfis (Paucker 1849: 182; Klöker 2005a: 300, 2014: 542). Viimane väide põhineb usutavasti Gadebuschi kirjameeste leksikoni andmeil (Gadebusch 1777: 128). Poeg Brockmanni leinatrükise andmetele toetudes võib väita, et ta sündis Schwaani linnas, Mecklenburgi hertsogkonnas 28. aprillil 1609 (Sandhagen 1648: D).

Tekib küsimus, kuidas on omavahel seotud asulad Schwaan, Gränzdorf ja Wigendorf. Juba XIII sajandil linnana mainitud Schwaan paikneb Rostocki ja Güstrow' vahel, Beke jõe Warnow' jõkke suubumise kohas. 
Schwaani linna lähiümbruses leiduv Wiegendorf või Wigendorf, õieti Wiendorf on väike asula, millel on üsna pikk ajalugu (esmamainimine 1356. aastal kujul dorffe Wiendorp, vt http://foerderverein-dorfkirche-wiendorf.de/seite3.html (30. VIII 2016)). Selle asukoht on Schwaanist umbes kolm kilomeetrit kirdes, teispool Warnow' jõge.

Schwaani ümbruses eraldi Gränz- või Grenzdorfi-nimelist asulat ei leidu. Küll aga on kaks asulat, mille nimi on Grenz: Groß Grenz ja Klein Grenz. Need asuvad Schwaanist kuus kilomeetrit loodes. Tänapäeval on mõlemad halduslikult Bröbberow' aleviga ühendatud. Et ainult Groß Grenzis on kirik, ehitatud XIV sajandil (vt http://www.gross-grenz.de/kirche.html (30. VIII 2016)), tuleb ilmselt isa Brockmanni üheks ametipaigaks pidada just seda Grenzi. Nagu tema matusetrükise tiitellehest selgub, töötas ta hingekarjasena põhikohaga Schwaanis, mille incorporirten filialen ehk abikirikud olid Grenzis ja Wiendorfis.

\section{Kokkuvõte}

Poeg Brockmanni ema ja isa surma puhul avaldatud matusetrükistes ilmunud järelehüüded heidavad mõningast valgust tulevase Tallinna gümnaasiumi kreeka keele professori põlvnemisele, lapsepõlvekodule ja kasvuoludele. Eriti isa Brockmanni järelehüüdest selguvad mitme perekond Brockmanniga seotud isiku omavahelised sugulus- ja hõimlussuhted ning isa Brockmanni noorpõlves sõlmitud tutvused.

Isa Brockmann oli nõrga tervisega, nii et abikaasal tuli teda tihti põetada. Isa Brockmanni matusetrükisest lähtuvalt võib täpsustada tema surmakuupäeva: see on 23. juuni 1626. Surres töötas ta Schwaani linna evangeelse koguduse pastorina, mille abikirikud asusid linna lähikonna asulates Grenzis ja Wiendorfis. Et pastori põhitöökoht oli Schwaanis, oli järelikult ka poeg Brockmann seal sündinud.

Need, kes kuulusid isa Brockmanni suhtlusringi ja avaldasid talle abikaasa surma puhul matusetrükises ilmunud leinaluuletuse kaudu kaastunnet, olid seotud mitte ainult Rostocki ülikooli usuteaduskonnaga, vaid neid ühendas vaimne avatus eelpietismi ja luterliku kiriku reformi suhtes. Sama usuline vaim vajutas kahtlemata pitseri ka poeg Brockmanni õpingutele samas ülikoolis. Järelikult võis ta mõni aasta hiljem Rostockist Tallinnasse siirdudes oma nii-öelda vaimses pagasis kaasas kanda poolehoidu eelpietistlikele ideedele. Näib koguni, et Brockmannide pere puutus kokku pietistlike vaadetega ja tundis nende suhtes poolehoidu läbi nelja põlvkonna.

\section{VEEBIALLIKAD}

CPR = Catalogus Professorum Rostochiensium. http://cpr.uni-rostock.de Förderverein Dorfkirche Wiendorf e. V. http://foerderverein-dorfkirche-wiendorf.de GEDBAS. Verein für Computer Genealogie. https://gedbas.genealogy.net Gemeinde Bröbberow. http://www.gross-grenz.de/kirche.html GESA = Gesamtkatalog deutschsprachiger Leichenpredigten. http://www.personalschriften. de/datenbanken/gesa.html 
Ib Keld Jenseni kodulehekülg. http://www.m.ikjensen.dk/jensen/index.html

MPR = Matrikelportal Rostock. http://matrikel.uni-rostock.de

Matrikel der Universität Rostock 1419-1760. Digitalisat der Originalhandschift. [Universitätsarchiv Rostock: 1.8 Matrikelbücher.] Rostock, 2010. http://rosdok.uni-rostock.de/ resolve/id/rosdok_document_0000000176

VD17 = Das Verzeichnis der im deutschen Sprachraum erschienenen Drucke des 17. Jahrhunderts. http://www.vd17.de

\section{KIRJANDUS}

Aarma, Liivi 2007. Põhja-Eesti vaimulike lühielulood 1525-1885. Kurzbiographien der Pastoren des Konsistorialbezirks Estland 1525-1885. Herdaminne för Estland[s] stift: kortbiografi[er] 1525-1885. Pastors of North Estonia: short biographies 1525-1885. Tallinn: [G. \& T. Aarma Maja OÜ].

Adelung, Johann Christoph 1801. Grammatisch-kritisches Wörterbuch der hochdeutschen Mundart. Kd 4, Seb-Z. Leipzig: Breitkopf und Sohn.

Bacmeister, Lucas 1607 = Christliche Leichpredigt/ gehalten bey der Leichbestätigung des Ehrwürdigen vnd Hochgelarten Herrn Valentini Schachterii, der heiligen Schrift Doctoris vnd Professoris in der Universitet, auch Pastoris der Kirchen zu S. Jacob in Rostock/ welcher in dem HErrrn seliglich entschlaffen/ den 12. Junij/ vnd hernach den 15. Junij/ am tage Viti Christlich zur Erden bestätet ist/ Anno 1607. Gehalten durch Lvcam Bacmeistervm, den Eltern der H. Schrifft Doctorn vnd Professorn, auch Superintendentem der Kirchen in der Stadt Rostock. / Rostock. Gedruckt bey Stephan Müllman. [Herzog August Bibliothek Wolfenbüttel; http://diglib.hab.de/drucke/q-147-4f-helmst-7s/start. htm (2. V 2020).]

Bacmeister, Lucas 1625 = Eine Christliche Leichpredigt/ Der weiland Erbarn/ Gottfürchtigen vnd Tugendsahmen Frawen / Margaretæ Scheffters/ Des Ehrwürdigen vnd Wolgelarten/ Herrrn M. Reineri Brockmanni, Pastoris der Kirchen zu Schwan/ Ehelichen Haußfrawen seligen/ zu letzten Ehren vnd ihrem lieben Eheman/ Brudern vnd Kindern zu troste/ Gehalten zu Schwan am 13. Sontag nach Trinitatis/ war der 11. Tagk Septembris Anno 1625. vnd auff begehren zum Druck verfertiget Durch Lucam Bacmeisterum, der H. Schrifft Doctorem, vnd Fürstlichen Meckelnburgischen Superintendentem zu Güstrow. Rostock/ Gedruckt durch Jochim Fueß/ Anno 1625. [Niedersächsische Staatsund Universitätsbibliothek; https://gdz.sub.uni-goettingen.de/id/PPN671004867 (4. V 2020).]

Bacmeister, Lucas $1627=$ Aller Gottseligen Weisen TrostSpiegel/ Auß dem 27. Psalm Davids v. 8. 9. 10. erkleret/ Bey der trawrigen Leichbegengnuß Des weyland Ehrwürdigen/ Achtbaren vnd Wolgelarten/ Ern M. Reineri Brocmanni, wolverdienten Pastoris der Kirchen vnd Christlichen Gemeine zu Schwan vnd incorporirten filialen. Den 27. Junij dieses lauffenden 1626. Jahrs/ daselst gehalten/ vnd auff der Kinder begehren in den Druck gebracht/ Durch Lucam Bacmeisterum, der H. Schrifft Doctorem vnd Fürstlichen Meckelnburgischen Superintendenten zu Güstrow. Gedruckt zu Rostock/ Durch Jochim Fueß/ Anno M.DC.XXVII. [Staatsbibliothek zu Berlin, Preußischer Kulturbesitz; http:// 
digital.staatsbibliothek-berlin.de/werkansicht?PPN=PPN682518824\&PHYSID=PHYS_ 0005\&DMDID=DMDLOG_0001 (25. VIII 2016).]

Bautz, Friedrich Wilhelm (toim) 1990. Biographisch-Bibliographisches Kirchenlexikon. Kd 1. Hamm (Westf.): Traugott Bautz.

Becker, Julius 1930. Verzeichnis der Leiter und Lehrer der Grossen Stadtschule zu Rostock seit der Gründung 1580 bis 1930. - Die Grosse Stadtschule zu Rostock in 3 1/2 Jahrhunderten. Eine Jubiläumsschrift. Toim Walther Neumann. Rostock: Carl Boldtsche Hofbuchdruckerei, lk 113-147.

Birket-Smith, Sophus (toim) 1890. Kjøbenhavns Universitets Matrikel. Kd 1, 1611-1667. Kjøbenhavn: Gyldendalske Boghandels Forlag.

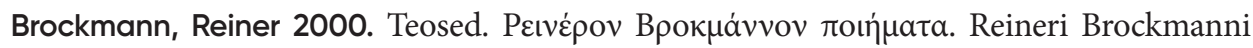
opera. Reiner Brockmann's Werke. Koost, toim Endel Priidel. Tartu: Ilmamaa.

Calmberg, Ernst Philipp Ludwig 1829. Geschichte des Johanneums zu Hamburg. Hamburg: Joh. Aug. Meissner.

Dittmer, Georg Wilhelm 1859. Genealogische und biographische Nachrichten über lübeckische Familien aus älterer Zeit. Lübeck: Dittmersche Buchhandlung.

EE $=$ Eesti entsüklopeedia. Kd 14, Eesti elulood. Tallinn: Eesti Entsüklopeediakirjastus, 2000, lk 40 .

Friedenthal, Meelis 2019. Akadeemilise teoloogia suunad Tartus Academia Gustavianas ja Gustavo-Carolinas. - Reformatsioon. Tõlked ja tõlgendused. (Libri et memoria 5. Eesti Rahvusraamatukogu toimetised 16.) Koost Piret Lotman. Tallinn: Eesti Rahvusraamatukogu, lk 165-183.

Gadebusch, Friedrich Konrad 1777. Livländische Bibliothek nach alphabetischer Ordnung. Kd 1. Riga: Johann Friedrich Hartknoch.

Gummelt, Volker 2005. Tarnow, Paul. - Religion in Geschichte und Gegenwart. Handwörterbuch für Theologie und Religionswissenschaft. Kd 8. Vierte, völlig neu bearbeitete Auflage Herausgegeben von Hans Dieter Betz, Don S. Browning, Bernd Janowski, Eberhard Jüngel. Tübingen: Mohr Siebeck, lk 42-43.

Hoche, Richard 1890. Scheffter, Zacharias. - Allgemeine Deutsche Biographie. Kd 30, Rusdorf-Scheller. Herausgegeben durch die Historische Commission bei der Königl. Akademie der Wissenschaften. Leipzig: Duncker \& Humblot, lk 688.

Kaufmann, Thomas 1997. Universität und lutherische Konfessionalisierung. Die Rostocker Theologieprofessoren und ihr Beitrag zur theologischen Bildung und kirchlichen Gestaltung im Herzogtum Mecklenburg zwischen 1550 und 1675. (Quellen und Forschungen zur Reformationsgeschichte 66.) Gütersloh: Gütersloher Verlagshaus.

Klöker, Martin 2005a. Literarisches Leben in Reval in der ersten Hälfte des 17. Jahrhunderts (1600-1657). Institutionen der Gelehrsamkeit und Dichten bei Gelegenheit. 1. osa. Darstellung. (Frühe Neuzeit 112.) Tübingen: Max Niemeyer Verlag.

Klöker, Martin 2005b. Literarisches Leben in Reval in der ersten Hälfte des 17. Jahrhunderts (1600-1657). Institutionen der Gelehrsamkeit und Dichten bei Gelegenheit. 2. osa. Bibliographie der Revaler Literatur. Drucke von den Anfängen bis 1657. (Frühe Neuzeit 112.) Tübingen: Max Niemeyer Verlag. 
Klöker, Martin 2014. Tallinna kirjanduselu 17. sajandi esimesel poolel (1600-1657). Haridusinstitutsioonid ja juhuluuletamine. Tlk Kristi Viiding. Tallinn: Teaduste Akadeemia Kirjastus.

Kõpp, Johann 1937. Laiuse kihelkonna ajalugu. Tartu: Eesti Kirjanduse Selts.

Lenz, Rudolf 1975. Gedruckte Leichenpredigten (1550-1750). - Leichenpredigten als Quelle historischer Wissenschaften. Toim R. Lenz. Köln-Wien: Böhlau Verlag, lk 36-51.

Leube, Hans 1924. Die Reformideen in der deutschen Lutherischen Kirche zur Zeit der Ortodoxie. Leipzig: Dörffling \& Franke.

Leube, Hans 1975. Ortodoxie und Pietismus. (Arbeiten zur Geschichte des Pietismus 13.) Bielefeld: Luther-Verlag.

Lumpe, Adolf 1996. Tarnow, Johann. - Biographisch-Bibliographisches Kirchenlexikon. Kd 11. Toim Friedrich Wilhelm Bautz, Traugott Bautz. Herzberg: Traugott Bautz, vg 504-508.

Mahlmann, Theodor 1996. Tarnow, Paul. - Biographisch-Bibliographisches Kirchenlexikon. Kd 11. Toim Friedrich Wilhelm Bautz, Traugott Bautz. Herzberg: Traugott Bautz, vg 526-540.

Muther, Theodor 1876. Bording, Jakob. - Allgemeine Deutsche Biographie. Kd 3, Bodev. Carlowitz. Herausgegeben durch die Historische Commission bei der Königl. Akademie der Wissenschaften. Leipzig: Duncker \& Humblot, lk 158.

Neumann, Walther 1930. Geschichte der Grossen Stadtschule zu Rostock. - Die Grosse Stadtschule zu Rostock in 3 1/2 Jahrhunderten. Eine Jubiläumsschrift. Toim W. Neumann. Rostock: Carl Boldtsche Hofbuchdruckerei, lk 7-95.

Paucker, H[ugo] R[ichard] 1849. Ehstlands Geistlichkeit in geordneter Zeit- und Reihefolge. Reval: Lindfors Erben.

Piibel. Vana ja Uus Testament. London: The British and Foreign Bible Society, 1968.

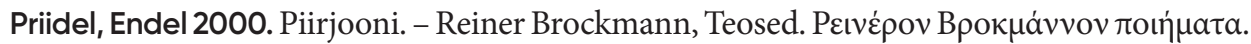
Reineri Brockmanni opera. Reiner Brockmann's Werke. Koost, toim E. Priidel. Tartu: Ilmamaa, 1k 15-30.

Raag, Raimo 2016. Reinerus Reineri Broocman: Ett liv i nordiska krigets skugga. - En fulständig swensk hus-håldsbok af Reinerus Reineri Broocman. En handbok i gårdsoch hushållsskötsel i vid mening från 1700-talets första hälft samt Broocmans värld och hushållsbok belyst i åtta artiklar av nutida forskare. Kd 2. Toim Håkan Tunón. Uppsala: Centrum för biologisk mångfald; Stockholm: Kungl. Skogs- och Lantbruksakademien, lk 871-908.

Roth, Fritz 1970. Restlose Auswertungen von Leichenpredigten und Personalschriften für genealogische und kulturhistorische Zwecke. Kd 6, Behandelte Personen mit den Nummern R 5001-R 6000. Boppard am Rhein: Selbstverlag Fritz Roth.

Roth, Fritz 1972. Restlose Auswertungen von Leichenpredigten und Personalschriften für genealogische und kulturhistorische Zwecke. Kd 7, Behandelte Personen mit den Nummern R 6001-R 7000. Boppard am Rhein: Selbstverlag Fritz Roth.

Saagpakk, Maris 2009. Reiner Brockmanns Briefe. - Autobiographisches Schreiben von der Frühen Neuzeit bis in die Gegenwart. Toim Mari Tarvas. Frankfurt am Main: Peter Lang, lk 51-68.

Sandhagen, Andreas 1648 = DER GERECHTEN TOD Auß dem Buch der Weißheit am 4. Das ist: Christlicher Leich-Sermon Beym Begräbniß Des Ehrwürdigen Achtbarn vnd 
Wolgelarten Herrn Reineri Brockmanns/ der Gemeine Gottes zu S. Catharinen in Ehstland gewesenen Pastoris, vnd des Wyrischen Districts wolverordneten Præpositi, Welcher/ nachdem Er am 29. Novemb. des nechstverstossenen 1647. Jahres gegen den Abend auff seinem Pfarrhofe zu Tristfer in GOtt seelig verschieden/ folgends am 14. januarij jßtlauffenden Jahres/ zu S. Olai in Reval mit Christlichen vnd gewöhnlichen Ceremonien zur Erden bestattet worden/ Auff desselben Begehren über diesen Text gehalten Von Andrea Sandhagen/ selbiger Kirchen bestalten Diacono. Reval/ Gedruckt bey Heinrich Westphal/ des Gymnasij Buchdrucker/ im Jahr 1648. [http://purl.uni-rostock.de/rosdok/ ppn748732896 (23. IV 2019).]

Scherer, Wilhelm 1878. Frischlin, Nicodemus. - Allgemeine Deutsche Biographie. Kd 8, Friedrich I von Sachsen-Altenburg-Gering. Herausgegeben durch die Historische Commission bei der Königl. Akademie der Wissenschaften. Leipzig: Duncker \& Humblot, lk 96-104.

Schlie, Friedrich 1901. Die Kunst- und Geschichts-Denkmäler des Grossherzogthums Mecklenburg-Schwerin. Kd 4, Die Amtsgerichtsbezirke Schwaan, Bützow, Sternberg, Güstrow, Krakow, Goldberg, Parchim, Lübz und Plau. Schwerin: Bärensprungsche Hofbuchdruckerei.

Schmaltz, Karl 1936. Kirchengeschichte Mecklenburgs. Kd 2, Reformation und Gegenreformation. Schwerin: Bahn.

Schreiber, Theodor 1884-1886. Artemis. - Ausführliches Lexikon der griechischen und römischen Mythologie. Kd 1, v 1, Aba-Evan. Toim Wilhelm Heinrich Roscher. Leipzig: B. G. Teubner, vg 558-608.

Siirak, Erna 1975. Brocmann, Reiner. - Eesti kirjanduse biograafiline leksikon. Toim Endel Nirk, Endel Sõgel. Tallinn: Eesti Raamat, lk 52.

Siirak, Erna 1995. Brocmann, Reiner. - Eesti kirjarahva leksikon. Koost, toim Oskar Kruus. Tallinn: Eesti Raamat, lk 67.

Sillem, Carl Hieronymus Wilhelm 1891. Die Matrikel des Akademischen Gymnasiums in Hamburg 1613-1883. Hamburg: Lucas Gräfe \& Sillem.

Stein, Johannes 1635. Beschreibung Des Herkommens/ Lebens vnd S. Absterbens Des weiland Ehrwürdigen/ Andächtigen vnd Wolgelarten Herrn Ernn. M. Iohannis Goltsteins, gewesenen Superintendenten des Ehrwürdigen Ministerii in Rostock/ vnd Pastoren der gemein zu S. Niclas daselbst. Aus seinem von jhme selbst gemachten Epitaphio in deutsche Rithmos vnd Versus Alexandrinos gesetzet/ Vnd Ihme zum ewigen Gedächtnis vnd Ehren auffgezeichnet/ Auch seiner lieben Haußfrawen vnd jetzo hochbetrübten Wittwen Der Ehr vnd Tugendsamen Dorothea Alwardes/ Zu gönstigen Ehren vnd Gefallen übersandt Durch M. Johannem Stein Prediger zu S. Niclas. Am Tage der Leich Bestättigung des S. Herrn welches war der 3 Martii. Anno M.DC.XXXV. [S.I.] [Sächsische Landesbibliothek - Staats- und Universitätsbibliothek Dresden; http://digital.slub-dresden.de/ id457633867 (26. VIII 2019).]

Ziegra, Christian 1770. Nicolaus Wilckens, weiland J. U. D. [Iuris Utriusque Doctor] und Archivarius der Stadt Hamburg, Hamburgischer Ehren-Tempel, in welchem eine Menge glaubwürdiger, und so viel möglich vollständiger Lebensbeschreibungen gelehrter und verdienstvoller Männer, die theils in theils ausser Hamburg gebohren worden, und daselbst im geistlichen und weltlichen Stande der Stadt gedienet haben, oder auch in 
einem Privatleben geblieben, oder auswärtig befördert worden sind, aufgestellt werden, aus den hinterlassenen Handschriften aufgerichtet von M. Christian Ziegra, der Hamb. Domkirche Canonicus. Hamburg: Schröder.

Zimmermann, Paul 1889. Reineccius, Reiner. - Allgemeine Deutsche Biographie. Kd 28, Reinbeck-Rodbertus. Herausgegeben durch die Historische Commission bei der Königl. Akademie der Wissenschaften. Leipzig: Duncker \& Humblot, lk 17-19.

Zimmermann, Paul 1926. Album Academiae Helmstadiensis. Kd 1, Album Academiae Juliae. V 1, Studenten, Professoren etc. der Universität Helmstedt von 1574-1636. Hannover: Selbstverlag der Historischen Kommission.

TEA = TEA entsüklopeedia. Kd 4, Becher-Burton. Peatoim Toomas Tamla. Tallinn: TEA Kirjastus, 2009.

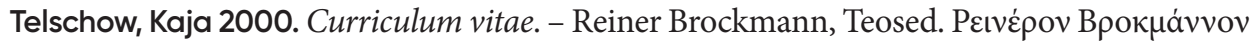

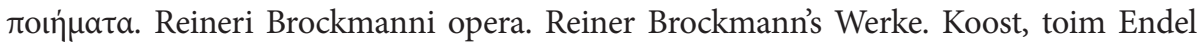
Priidel. Tartu: Ilmamaa, lk 33-40.

Tholuck, August 1854. Vorgeshichte des Ratsionalismus. Kd 1, Das akademische Leben des siebzehnten Jahrhunderts mit besonderer Beziehung auf die protestantisch-theologischen Fakultäten Deutschlands, nach handschriftlichen Quellen. V 2, Die akademische Geschichte der deutschen, skandinavischen, niederländischen, schweizerischen Hohen Schulen. Halle: Eduard Anton.

Vahtre, Sulev 2005. Aus dem Leben und Werk von Pastor Reiner Broocmann (ca 16401704). - Die baltischen Länder und der Norden. Festschrift für Helmut Piirimäe zum 75. Geburtstag. (Nordistica Tartuensia 13.) Toim Mati Laur, Enn Küng. Tartu: Akadeemiline Ajalooselts, lk 224-247.

Viiding, Kristi 2015. Noor Brockmann luuletamisest. - Keel ja Kirjandus, nr 11, lk 777-791.

Wallmann, Johannes 1970. Philipp Jakob Spener und die Anfänge des Pietismus. (Beiträge zur historischen Theologie 42.) Tübingen: J. C. B. Mohr (Paul Siebeck).

Wieselgren, Greta 1964-1966. Johann Fischer. - Svenskt biografiskt lexikon. Kd 16, FichGehlin. Toim Erik Grill. Stockholm: [Svenskt biografiskt lexikon], lk 56-61.

Willgeroth, Gustav 1924. Die Mecklenburg-Schwerinschen Pfarren seit dem dreißigjährigen Kriege. Mit Anmerkungen über die früheren Pastoren seit der Reformation. Wismar: Selbstverlag des Verfassers.

Willgeroth, Gustav 1925a. Die Mecklenburg-Schwerinschen Pfarren seit dem dreißigjährigen Kriege. Mit Anmerkungen über die früheren Pastoren seit der Reformation. Kd 2. Wismar: Selbstverlag des Verfassers.

Willgeroth, Gustav 1925b. Die Mecklenburg-Schwerinschen Pfarren seit dem dreißigjährigen Kriege. Mit Anmerkungen über die früheren Pastoren seit der Reformation. Kd 3. Wismar: Selbstverlag des Verfassers.

Raimo Raag (snd 1953), PhD, Uppsala ülikooli soome-ugri keelte (eesti keele) professor, tänapäeva keelte osakond (Box 636, SE-751 26 Uppsala, Rootsi), raimo.raag@moderna.uu.se 


\section{Brockmanniana. The printed funeral sermons on the occasion of the death of Reiner Brockmann's parents}

Keywords: funeral poem, family history, Greek, Pietism, Rostock University, Schwaan

Based on biographical data in two funeral sermons printed in 1625 and 1627, the article introduces the family of the poet and future professor of Greek at the Gymnasium in Tallinn, Reiner Brockmann (1609-1647), and, more specifically, the social circle of his parents, notably his father, the Reverend Reiner Brockmann (1568-1626). It appears that those who expressed their condolences in the form of funeral poems in Latin dedicated to the deceased spose of Reverend Brockmann, Margareta Scheffter (1570-1625), were not only associated with the Faculty of Religion of Rostock University, but were also united by a certain spiritual openness to early Pietism. It even seems that exposure to, and perhaps some sympathy for Pietist views continued in the Brockmann lineage through four generations. Further, the funeral sermons make it possible, inter alia, to clarify both the time of Reverend Brockmann's death, June 23, 1626, and the place of birth of his son, the younger Brockmann: the small town of Schwaan in the Duchy of Mecklenburg. The poem written in Greek by him on the occasion of the death of his father is also republished and briefly commented on.

Raimo Raag (b. 1953), PhD, Professor of Finno-Ugric languages (Estonian language), Uppsala University, Department of Modern Languages (PO Box 636, SE-751 26 Uppsala, Sweden), raimo.raag@moderna.uu.se 